\title{
Corrosion of steel structures in sea-bed sediment
}

\author{
XIUTONG WANG ${ }^{\dagger, *}$, JIZHOU DUAN ${ }^{*,}$, YAN LI $I^{\dagger}$, JIE ZHANG ${ }^{\dagger, *}$, SHIDE MA ${ }^{\dagger}$ and \\ BAORONG HOU
}

Ocean University of China, Qingdao 266003, China

${ }^{\dagger}$ Institute of Oceanology, Chinese Academy of Sciences, Qingdao 266071, China

${ }^{\ddagger}$ Graduate School of the Chinese Academy of Sciences, Beijing 100039, China

MS received 20 September 2004; revised 28 January 2005

\begin{abstract}
Seabed sediment (SBS) is a special soil that is covered by seawater. With the developments in marine oil exploitation and engineering, more and more steel structures have been buried in SBS. SBS corrosion has now become a serious problem in marine environment and an important issue in corrosion science. In this paper, approach in the field of SBS corrosion is reviewed. Electrochemical and microbial corrosion factors, corrosion mechanism, measurement of metal corrosion rate, corrosion evaluation and prediction of corrosion are also discussed here.
\end{abstract}

Keywords. Seabed sediment; corrosion factor; corrosion mechanism; corrosion evaluation.

\section{Introduction}

Seabed sediment (SBS) corrosion is an important topic in marine environment corrosion science. In terms of corrosion locality, marine environment can be divided into atmospheric zone, splash zone, tidal zone, immersed zone, and seabed sediment zone. Generally, it is considered that the seabed sediment zone has the least corrosiveness (Hou 1998). However, some studies have voiced in different tone due to the complexity of the corrosion. For example, the steel corrosion varies in ten-time difference in different zones having different corrosion environment (Schmide 1980). Corrosion under anaerobic environment can make marine pipes perforated. Development in marine oil exploitation and engineering including marine cables, steel rigs, pipelines and other marine facilities, is increasing quickly demanding diligent and integrated investigation and research on corrosion. Therefore, scientific solution and reference to corrosion in marine oil exploitation flat and seabed pipelines can be provided. Since the 1980s, many systematic investigations have been performed by some researchers (King 1980; Li et al 1997). A brief summary of the advancement made in SBS corrosion study is presented in this paper.

\section{SBS corrosion factor}

SBS is a special soil beneath seawater. It is soaked to some extent. In this two-phased system, there is no sole gas phase. The SBS termed in this paper is defined mainly as surface layer SBS on shallow sea continental shelf. Its

\footnotetext{
*Author for correspondence (duanjz@ms.qdio.ac.cn)
}

physical and chemical characters are different from land soil, salina soil and tideland soil. Therefore, the method of study is specifically particular.

The SBS corrosion character depends on many factors (Hou et al 2001). In practice, the factors can be divided into two types, i.e. the electrochemical and microbial ones.

\subsection{Electrochemical corrosion factor}

Electrochemical corrosion directly relates to electrochemical actions that are influenced by temperature, particle size, electrical resistance, salinity, dissolved oxygen, $\mathrm{pH}$ value etc.

2.1a Temperature: Temperature is an important factor which affects the kinetic process of electrode reaction. When temperature rises, the substance diffusion on electrode surface and in solution accelerates. A study (Ma et al 1995) indicated that the SBS temperature influences greatly on steel corrosion. By the experiment on temperature range, corrosion rate increases as temperature rises. The corrosion rate at high temperature can be four times bigger than at low temperature.

2.1b Particle size: In corrosion study, the particle size of SBS can be divided into sand $(>0.1 \mathrm{~mm})$, silt $(0.1$ $\sim 0.01 \mathrm{~mm})$, and mud $(<0.01 \mathrm{~mm})$. There is a clear relationship between the size and steel corrosion rate $(\mathrm{Li}$ and Hou 1997). Because coarser particle has stronger water permeability, so, it tends to react with the dissolved oxygen in sea water and speed up the corrosion process. Figure 1 shows three-year corrosion rate of A3, $16 \mathrm{Mn}$, and 20\# steel in mud and sand, respectively. This indicated a typical electrochemical corrosion process of the oxygen 
transportation control. As the steel rigs and pipelines are being used widely across different zones of SBS, galvanic corrosion would occur (Zhang et al 1993). Figure 2 shows the corrosion rate with different grain sizes of mild steel (Duan et al 2002).

2.1c Electrical resistance: Electrical resistance is the reflection of SBS electrical conductivity. The resistance of surface layer SBS changes in the scope of several ten to several hundred $\mathrm{ohm} \cdot \mathrm{cm}^{2}$, and it increases with the burial depth ( $\mathrm{Li}$ et al 1997). It is known that the resistance has positive linear relation with SBS particle size. Generally the SBS with the coarser particle has bigger resistance. The resistance has important influence on macro cell corrosion as well.

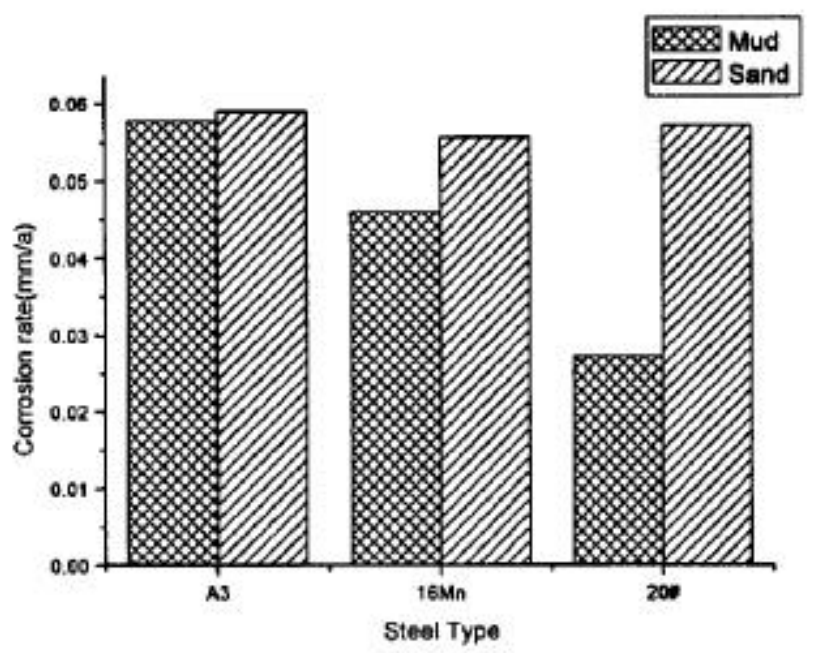

Figure 1. A three-year corrosion rate of A3, $16 \mathrm{Mn}$, and 20\# steel in mud and sand.

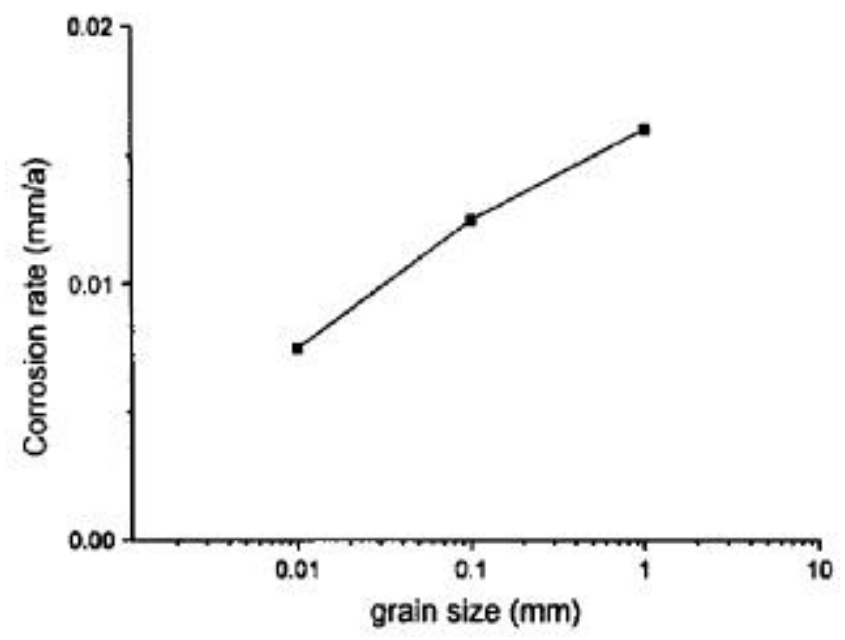

Figure 2. Corrosion rate vs grain size of mild steel. 2.1d Salinity: The salinity here means the general salinity including SBS and its bearing on water and ions such as $\mathrm{Cl}^{-}, \mathrm{SO}_{4}^{2-}$ etc which have great influence on corrosion. The higher the salinity, the smaller the impedance, the bigger the corrosion rate. On the other hand, $\mathrm{Cl}^{-}$ and $\mathrm{SO}_{4}^{2-}$ have remarkable influence on corrosion (Cao 1985). Increasing concentration of $\mathrm{Cl}^{-}$can speed up metal anodic reaction and make the corrosion stronger. In the oxygen concentration cell, $\mathrm{Cl}^{-}$would accelerate anodic dissolution rate. In the organism and anaerobic conditions, $\mathrm{SO}_{4}^{2-}$ can participate in the depolarization reaction which can speed up steel corrosion through microbe action.

2.1e Dissolved oxygen: Oxygen dissolved in sea water acts as an important depolarizer. In shallow sea and continent shelf area, photosynthesis by phytoplankton creates a difference in dissolved oxygen between surface layer and bottom sea water. As no pure gas phase exists, the exchange of substance and energy depends only on the surface SBS, therefore, it is very slow in the bottom sea water. Due to very limited oxygen content there, the SBS corrosion is under oxygen-deficient or anaerobic condition. The corrosion rate in this case is controlled by diffusion step of oxygen depolarization. If no account of microbiologically influenced corrosion (MIC) is considered, the corrosion rate is low (Zhang et al 1993).

2.1f $p H$ value: Sea water is a complicated system. However, its $\mathrm{pH}$ value is quite consistent varying from 8-8.2 in normal sea (Schumacher 1979). The $\mathrm{pH}$ value could be changed in polluted sea area. The $\mathrm{pH}$ value in SBS tends to be close to that of the surrounding sea water. The $\mathrm{pH}$ value in surface layer SBS in Liaodong Bay, Bohai Sea, the East China Sea, and the Tonkin Gulf of the South China Sea is in the range of 6.0 $10 \cdot 0$ in different places (Ma et al 1995; Li et al 1997). The $\mathrm{pH}$ range for growth of SRB is $6.5 \sim 8.5$ with optimum being $7.2 \sim 7.5$, some alkalophilic bacterium may change the $\mathrm{pH}$ value of SBS (Boussiba 1989). Oxidation of elemental sulphur results in the formation of sulphate and hydrogen ions and sulphur oxidation characteristically results in lowering of $\mathrm{pH}$ (Rajasekar et al 2005). Within this $\mathrm{pH}$ range, it is favourable for propagation of anaerobic bacteria.

\subsection{MIC factors}

MIC factors include mainly sulphate-reducing bacteria (SRB) content, redox potential $(E h)$, sulfur potential $(E s)$, the ratio of $\mathrm{Fe}^{3+}$ to $\mathrm{Fe}^{2+}$, organism content and so on.

2.2a SRB content: In SBS environment, MIC is mainly SRB corrosion. Generally speaking, SRB distributes widely in SBS in different contents in different sea areas. For example, the SRB content in Liaodong Bay SBS is $0 \sim 460$ unit per $g$ wet mud, and that in the South China Sea, it is $0 \sim 9 \cdot 3$ by most possible number (MPN) method (Ma 
et al 1995; Li et al 1997). In actuality, as the bacteria in sediment is not cultivable, the real bacteria content is much higher (Colwell and Grimes 2000). Many studies have been done on the effect of SRB content on metal corrosion (Fischer 1981; Ye et al 1985). Some studies indicated that the SRB can accelerate metal corrosion. Fischer (1989) found that big SRB propagation can increase the corrosion $6 \sim 7$ times. Ye et al (1985) indicated that the corrosion rate of four kinds of metals which were buried in sea mud has direct relation with SRB content. Zhang et al (1993) indicated that the corrosion rate of $\mathrm{A} 3,16 \mathrm{Mn}$ and $20 \#$ steel in sea mud with bacteria is $5 \cdot 5,4 \cdot 0,4.5$ times, respectively as that without bacteria.

2.2b Eh, Es, $\mathrm{Fe}^{3+} / \mathrm{Fe}^{2+}$ and organism content: All these factors affect SRB corrosion. Favourable anaerobic condition for best SRB growth is $\mathrm{pH}=6 \sim 9, t=25 \sim 35^{\circ} \mathrm{C}$, some water, sulphate, organism and $\mathrm{Fe}^{2+}$. It has been reviewed that the growth of SRB in marine environments causes significant modifications of many physicochemical parameters at the steel/seawater interface, including local changes in $\mathrm{pH}$ and redox potential values and other anion and cation concentrations (Videla 2000). In SBS, the condition is generally met. On the other hand, the value of Eh can indicate the oxidation and reduction state of SBS. Generally, corrosion under anaerobic condition of $-200 \mathrm{mV}$ is very extensive (American ANSI standard).

Besides the electrochemical and MIC factors affecting the SBS corrosion, some other factors should also be considered. Sediments are the ultimate sink for contaminants in the marine environment, and physical processes of sedimentation influence the distribution and accumulation of these contaminants (Wheeler et al 1980). In polluted area, variation in the concentration of trace metals in sediments can change the corrosion of structures (Ruiz and Saiz-Salinas 2000). Movement of surface layer water caused by sea bottom flow is also a considerable factor. Because of the ocean current, the SBS is often in an active flow condition, which can cause the erosion and stress corrosion.

\section{SBS corrosion mechanism}

According to corrosion environmental characteristics, SBS corrosion can be divided into electrochemical and MIC.

\subsection{Electrochemical corrosion}

In SBS corrosion, if no account of MIC is considered, diffusion of the oxygen is a main corrosion factor, which can determine corrosion rate of steel. As the dissolved oxygen in SBS is limited and the oxygen exchange is very slow, the corrosion rate of steel is quite low. The corrosion in seabed sediment was mainly determined by the macrogalvanic cell (oxygen concentration difference cell) (Li et al 2000). Two major types of corrosion caused by electrochemical action are galvanic corrosion and local corrosion.

3.1a Galvanic corrosion: For large-sized sea bottom facilities such as pipelines, when they cross different types of SBS, because of imbalance of dissolved oxygen in SBS, there would be a large potential difference which can bring about corrosion current, then galvanic corrosion occurs. Some researches indicated (Zhang et al 1993) that when steel structure buried in sea soil for a long time, the part buried in finer sediment is anode and is affected by accelerated corrosion to a certain extent. However, the part buried in coarser sediment is cathode and is protected to some extent.

3.1b Localized corrosion: Localized corrosion is mainly self-catalyst effect corrosion caused by oxygen difference (Cao 1985), such as pitting corrosion and crevice corrosion. The main reason is imbalance between anode current density and cathode current density on metal surface of rich oxygen and anaerobic regions. To make it clear for SBS corrosion mechanism, it is necessary to do more analysis and research on the corrosion product. Through Mössbauer spectroscopies and X-ray diffraction analyses on the corrosion product of steel in SBS (Yu and Wang 1987; Hou and Li 1998), conclusion has been made: (i) in the early stages of SBS corrosion, the effect of oxygen diffusion on corrosion rate is low, while with rust layer occurrence, it increases remarkably, (ii) the rust layer of carbon steel and low alloy steel in sea mud has only one layer and has sea mud stuck on it, mainly because it was formed in the absence of oxygen, so it is different from that in sea water. In sea water the primary corrosion product, $\mathrm{Fe}(\mathrm{OH})_{2}$, formed in the early stages of corrosion were all oxidized to $\alpha-\mathrm{FeOOH}$ or $\mathrm{Fe}_{3} \mathrm{O}_{4}$ because oxygen is rich in sea water ( $\mathrm{Li}$ et al 1998). Actually, for steel immersed in sea water or buried in SBS, the formation of rust and transformation is complex, the bacteriological role may be a key process (Jeffrey and Melchers 2003; Duan et al 2003). The formation of iron oxides(rust) and their transformation to iron sulfides should be studied further.

\section{$3.2 M I C$}

Corrosion caused by SRB is generally considerable under SBS environment (Huang et al 2004), which is often a localized corrosion (sometimes can even make the pipelines perforated). The corrosion product is usually sulfide with black colour and odd smell.

Kuhr (1934) realized first the importance of SRB in soil. He considered that under the condition of insufficient oxygen, SRB reduces sulphate to hydrogen sulfide $\left(\mathrm{H}_{2} \mathrm{~S}\right)$, and the product reacts with iron ion to produce 
FeS. Recent results agree on the finding, but they do not consider hydrogen as the necessary electron transferer. King and Miller (1971) point out that the sulphide and iron ion react and produce $\mathrm{FeS}_{x}$, and $\mathrm{FeS}_{x}$ closely attaches to the steel surface to compose an electrochemical cell. Action of SRB can continue to provoke this type of cell. Corrosion of mild steel during aerobic/anaerobic biofilm accumulation was classified as aerobic corrosion and SRB-enhanced corrosion (Lee et al 1993). Under the action of SRB, average corrosion rate of steel is not less than $0.1 \mathrm{~mm} / \mathrm{a}$, while that of pitting corrosion can even reach $0.7 \mathrm{~mm} / \mathrm{a}$ relating to the $\mathrm{FeS}_{x}$ density. Observation indicated that in anaerobic area, oxygen can promote greatly the steel corrosion rate. According to the laboratory simulation on buried specimen in soil with SRB, through the X-ray diffraction and analysis technology, Jack et al (1998) proved that when SRB is in existence, the alternate anaerobic and aerobic conditions can accelerate the steel corrosion greatly. This is because $\mathrm{FeS}_{x}$ has been oxidized to element sulfur, and the existence of sulfur leads to a higher corrosion rate to $1 \mathrm{~mm} / \mathrm{a}$. Recently, a new anaerobic corrosion mechanism has been proposed, in that the electron could be transferred directly between a new SRB-like anaerobic bacteria and zero value iron by hydrogenase and cytochrome (Dinh et al 2004). Other authors also suggested bio-produced hydrogenase and other organic molecules may have important role in the anaerobic organism corrosion (Da Silva et al 2004; Van Ommen et al 1995).

However, SRB corrosion not only transfers the iron to ferrous sulfide to induce homogeneous corrosion and pitting corrosion, but also produces hydrogen sulfide to make high strength steel material to crack with stress corrosion (Batt et al 2002). Moreover, the hydrogen sulfide is highly poisonous and health risky.

\section{Measurement of metal corrosion rate in SBS}

In sea bottom project design, the metal corrosion rate in SBS and its measurement are major concerns for their direct association with metal corrosion monitoring. At present, the measurement can be divided into in situ measurement and laboratory measurement including simulation buried specimen and electrochemical measurement.

\subsection{In situ measurement method}

In situ measurement is similar to buried specimen on the spot on land soil. In the 1950s, American researcher piled long plate and steel rig made of iron and its alloy from sea bottom to atmosphere zone (Schumacher 1979). Basic corrosion data of some metal was collected in each corrosion zone according to weight loss method. Similar researches have also been conducted in Germany, Japan and Russia. In addition, the "transplanting and burying" (Ma et al 1995) method is easier than the classical weight loss method, and can obtain more accurate corrosion data of metal in SBS.

\subsection{Laboratory measurement method}

Laboratory measurement includes simulation and electrochemical methods. Laboratory simulation can simulate the SBS corrosion environment with experimental equipments. It can be integrated with marine corrosion experiment station, and use conventional scientific method to obtain the data. Electrochemical method can effectively measure instantaneously corrosion rate. Some of the electrochemical methods used have been applied widely in land soil corrosion rate measurement (Scully and Bundy 1985; Chang 1988), such as linear polarization and dynamic polarization curve methods (Ma et al 1996). In addition, the polarization curve and electrochemical impedance spectra (EIS) methods are time-saving and stable in a wide-range, and they are expected to be applied in SBS corrosion widely.

However, there are many negative aspects in electrochemical method which need modification such as the effect of ohmic drop (Diard et al 1998). In addition, because of the complexity of the SBS with SRB, the laboratory measured electrochemical corrosion rate is probably not in accordance with the real data, some measures should be added to mend the result.

\section{SBS corrosion evaluation and prediction}

The SBS corrosion evaluation and prediction is based on weight loss method. Single or multiple corrosion factors in certain sea areas are used to judge and predict the corrosion nature of SBS.

In recent years research is growing in number on corrosion investigation and evaluation of land soil. The standard of the investigation has varied from single item to multiple items. Since 1988, the life prediction for buried land pipes with mathematical model were put forward. So were other models to evaluate and predict the soil corrosion character such as fuzzy clustering analysis method (Duan et al 2004), fuzzy gray theory and neural net method.

Because SBS is a special soil, the corrosion research on SBS has great significance for preventing marine structures from corrosion damage. King (1980) evaluated regionally the SBS corrosion data of the North Sea through weighted factor analysis. Fischer (1981) reported the corrosion rate of steel in surface sediment and the effect of SRB on corrosion. Through investigation on SBS factors in Liaodong Bay by weighted factor analysis, Ma and Huang (1998) described the surface sediment corrosion spectrum, where two-factor evaluation analysis 
on SBS corrosion based on the analysis of Northern Bay SBS was done.

Although evaluation and prediction of SBS corrosion has achieved great development, available corrosion data of SBS has yet been very limited, and selection of evaluation model is difficult. To build up appropriate model, detailed investigation is needed to enrich the data base in the field.

\section{Conclusions}

Research on SBS corrosion is still in its developing stage, and some problems need further study such as in situ measurement technology of corrosion factor, the MIC mechanism and the influence of MIC. With development in marine industry, new ocean regions are continually exploited, demanding more research on the SBS corrosion.

\section{Acknowledgements}

The work was financially supported by the Natural Science Foundation of China (No. 40376023, 40406022) and the CHINA National Offshore Oil Corporation (CNOOC).

\section{References}

Batt C et al 2002 Corros. Eng. Sci. \& Technol. UK 37194

Boussiba S 1989 Plant Cell Physiol. 30303

Cao Chunan 1985 The electrochemical corrosion theory (Beijing: The Chemistry Industry Press) p. 316

Chang Shouwen 1988 J. Corros. \& Protection of China 837

Colwell Rita R and Grimes D Jay (eds) 2000 Nonculturable microorganisms in the environment (Washington, DC: ASM)

Da Silva S, Basseguy R and Bergel A 2004 J. Electroanal. Chem. 56193

Diard J P, Le Gorrec B and Montella C 1998 Corros. Sci. 40 495

Dinh Hang T et al 2004 Nature 427829

Duan Jizhou et al 2002 Mater. \& Corros. 53845

Duan Jizhou et al 2003 13th Asia-pacific corrosion control conference (Osaka, Japan: Osaka University) 16
Duan Jizhou, Huang Xingde and Hou Baorong 2004 Proceedings of the 3rd international conference on ESCCD, (Qingdao, China: China Science and Technology Press) 9

Fischer K P 1981 Mater. Perf. 2041

Fischer K P 1989 ASTM 119

Hou Baorong 1998 Marine corrosion: Theory and application (Beijing: Science Press)

Hou Baorong and Li Yantao 1998 Studia Marina Sinica 13119

Hou Baorong et al 2001 Bull. Mater. Sci. 24253

Huang Yanliang, Duan Jizhou and Ma Shide 2004 Mater. \& Corros. 5546

Jack J R et al 1998 Corrosion 54246

Jeffrey Robert and Melchers Robert E 2003 Corros. Sci. 45693

King R A 1980 Mater. Perf. 1939

King R A and Miller J D A 1971 Nature 233491

Kuhr Van der Vlugt 1934 Water (The Hague) 18117

Lee et al 1993 Biofouling 7217

Li Xiangyun et al 1997 Tropic Ocean 1690

Li Yantao and Hou Baorong 1997 Chin. J. Oceanol. Limnol. 28 179

Li Yantao et al 1998 Chin. J. Oceanol. Limnol. 29651

Li Yantao, Li Yanxu and Hou Baorong 2000 Mater. \& Corros. 51570

Ma Shide and Huang Yanliang 1998 Chin. J. Oceanol. Limnol. 16253

Ma Shide, Zhu Sulan and Sun Jiarui 1995 Marine Science 510

Ma Shide, Zheng Guoan and Li Yantao 1996 Chin. J. Oceanol. Limnol. 14154

Rajasekar et al 2005 Corros. Sci. 47257

Ruiz J M and Saiz-Salinas J I 2000 Marine Environ. Res. 49 307

Schmide R L 1980 Pacific Northest Tab 45

Schumacher M 1979 Sea water corrosion handbook (New Jersey: Noyes Data Corporation)

Scully J R and Bundy K J 1985 Mater. Perf. 2418

Van Ommen F, Bryant R D and Laishley E J 1995 Anaerobe 1 351

Videla H A 2000 Biofouling 1537

Wheeler et al 1980 Environ. Geol. 3163

Ye Dezan, Liang Ziyuan and Yao Ruimei 1985 Oceanogr. Trans. 7650

Yu Xuan and Wang Yuanxi 1987 The selection of marine corrosion and protection conference (Qingdao: Ocean Press) 6

Zhang Jinglei, Hou Baorong and Guo Gongyu 1993 Chin. J. Oceanol. Limnol. 11172 